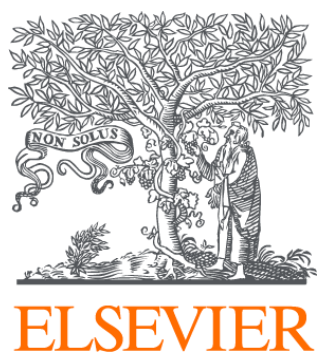

Since January 2020 Elsevier has created a COVID-19 resource centre with free information in English and Mandarin on the novel coronavirus COVID-

19. The COVID-19 resource centre is hosted on Elsevier Connect, the company's public news and information website.

Elsevier hereby grants permission to make all its COVID-19-related research that is available on the COVID-19 resource centre - including this research content - immediately available in PubMed Central and other publicly funded repositories, such as the WHO COVID database with rights for unrestricted research re-use and analyses in any form or by any means with acknowledgement of the original source. These permissions are granted for free by Elsevier for as long as the COVID-19 resource centre remains active. 


\title{
The European Association of Urology COVID Intermediate-priority Group is Poorly Predictive of Pathological High Risk Among Patients with Renal Tumours
}

\author{
Pranav Satish $^{a}$, Teele Kuusk ${ }^{b}$, Nick Campain ${ }^{b}$, Yasmin Abu-Ghanem ${ }^{b}$, Joana Neves ${ }^{b}$, \\ Ravi Barod $^{b}$, Pranav Satish $^{a}$, Faiz Mumtaz $^{b}$, Prasad Patki $^{b}$, Maxine Tran $^{b}$, \\ My-Anh Tran-Dang ${ }^{c}$, Lee Grant ${ }^{d}$, Tobias Klatte ${ }^{e}$, Axel Bex $^{a, b, *}$
}

The European Association of Urology Guidelines Office formed a Rapid Reaction Group (EAU GORRG) on March 19, 2020 [1] in response to the need for swift changes during the COVID-19 pandemic. In brief, the EAU GORRG guidelines assigned patients with suspected renal cell carcinoma (RCC) to low-, intermediate-, and high-priority groups according to their clinical TNM stage (Supplementary Table 1) [2]. Priority group allocation determined the extent to which surgery was postponed. Despite vaccine rollout, strain on health care resources is still widespread, especially in our London centre, where national lockdown was still in place at the time of writing. Thus, the need to assess the efficacy of this system is clear, as decisions to postpone interventions must be justified by the level of clinical harm that delayed treatment could incur. To evaluate the EAU GORRG guidelines, we assessed the extent to which priority groups matched postoperative pathological risk, determined according to the 2003 Leibovich score (LS) [3].

We compared the GORRG priority groups with postoperative pathological reports for 351 patients with biopsyproven or suspected RCC (Supplementary Table 2). LS 0-2 was considered to correspond to low GORRG priority, LS 3-5 to intermediate priority, and LS $>5$ to high priority. As the EAU intermediate-priority group encompasses the widest range of tumour sizes ( $>4 \mathrm{~cm}$ to $\leq 10 \mathrm{~cm}$ ), we evaluated risk migration to either low or high Leibovich risk for each $1-\mathrm{cm}$ increment within this group.

The least concordance between GORRG priority group and pathological risk occurred in the intermediate-priority group. A total of 102 patients (48\%, 95\% confidence interval [CI] 41-55\%) were incorrectly prioritised, 35 of whom (16\%, 95\% CI 12-22\%) were actually at high risk (Fig. 1). Analysis of the intermediate-priority group by tumour size interval revealed a higher likelihood of a change to low risk for cT1b $(4-7 \mathrm{~cm})$ tumours than for cT2a tumours (7-10 cm; Fig. 1B). More precisely, $45 \%$ (95\% CI 33-57\%) of all lesions $>4 \mathrm{~cm}$ and $<5 \mathrm{~cm}$ would be migrated to low risk (Supplementary Table 3 ). In fact, our centre would have been marginally more accurate by including tumours $<5 \mathrm{~cm}$ in the GORRG low-priority group, rather than $<4 \mathrm{~cm}$. Conversely, we found that among cT2a tumours ( $>7 \mathrm{~cm}$ to $\leq 10 \mathrm{~cm}$ ), $32 \%$ (95\% CI 22-45\%) were assigned LS high risk versus only $13 \%$ (95\% CI $8-19 \%$ ) of cT1b tumours $(>4 \mathrm{~cm}$ to $\leq 7 \mathrm{~cm}$; Supplementary Table 4). With higher risk observed for $16 \%$ (95\% CI 11-22\%) of patients in the EAU intermediatepriority group and $16 \%$ (95\% CI 10-25\%) in the low-priority group, some patients may experience poorer outcomes if their treatment is deferred. Recent work by Srivastava et al [4] suggests that a delay in care of 3 mo for cT1b-cT2b tumours does not lead to greater upstaging rates or shorter overall survival. However, their study had a relatively short follow up period and only considered upstaging to pT3a in the pre-COVID era.

Overall, the system erred on the side of caution, with the GORRG guidelines overestimating risk for 67 patients (19\%, 95\% CI 15-24\%), compared to the 50 patients (14\%, 95\% CI $11-$ $18 \%$ ) whose risk was underestimated. However, the cT2a intermediate-priority subgroup, in which almost one-third of the patients were upgraded to high risk, constitutes a possible exception. For future use, we therefore recommend minimising deferred interventions for intermediate-priority patients with cT2a RCC as much as possible. Conversely, at times of severely reduced resources, centres may consider intermediate-priority tumours of $<5 \mathrm{~cm}$ as low priority. 
A)

Low $94(27 \%)$

Low $133(38 \%)$

Intermediate 214 (61\%)

Intermediate 137 (39\%)

B)

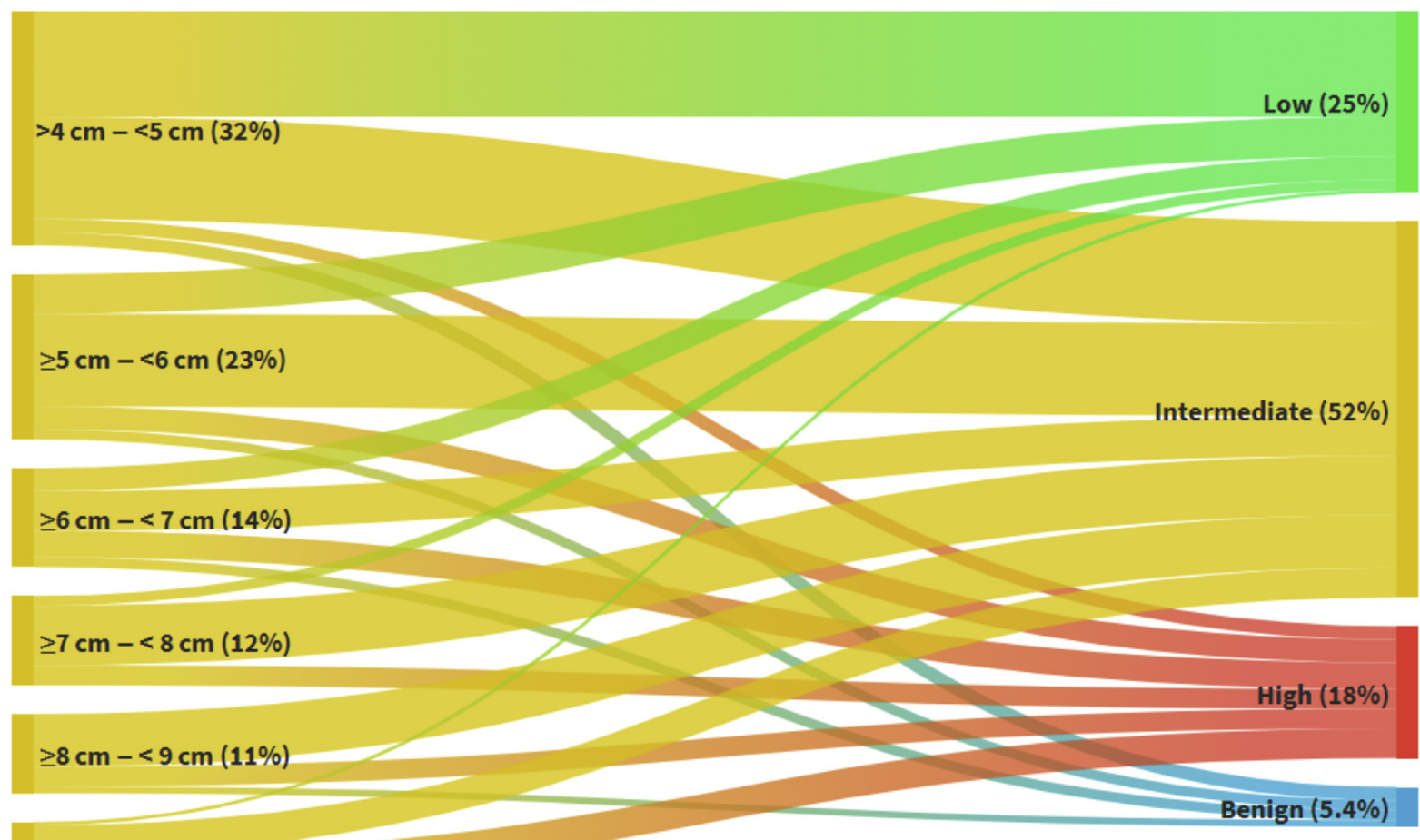

$\geq 9 \mathrm{~cm}-<10 \mathrm{~cm}(8.6 \%)$

Fig. 1 - Sankey diagrams showing matching of European Association of Urology priority groups (left) to risk according to the Leibovich score (right) for patients with renal cell carcinoma. $(A)$ Whole cohort $(n=351)$ and $(B)$ stratification of the intermediate-priority group $(n=214)$ by 1 -cm increments in tumour size.

Please cite this article in press as: Satish P, et al., The European Association of Urology COVID Intermediate-priority Group is Poorly Predictive of Pathological High Risk Among Patients with Renal Tumours. Eur Urol (2021), https://doi.org/10.1016/j. eururo.2021.05.010 
Conflicts of interest: The authors have nothing to disclose.

\section{Appendix A. Supplementary data}

Supplementary material related to this article can be found, in the online version, at doi:https://doi.org/10.1016/j. eururo.2021.05.010.

\section{References}

[1] Ribal MJ, Cornford P, Briganti A, et al. European Association of Urology Guidelines Office Rapid Reaction Group: an organisation-wide collaborative effort to adapt the European Association of Urology guidelines recommendations to the coronavirus disease 2019 era. Eur Urol 2020;78:21-8. http://dx.doi.org/10.1016/j.eururo.2020.04.056.

[2] Amin MB, Edge SB, Greene FL, et al. AJCC cancer staging manual. Cham, Switzerland: Springer International Publishing; 2017.

[3] Leibovich BC, Blute ML, Cheville JC, et al. Prediction of progression after radical nephrectomy for patients with clear cell renal cell carcinoma. Cancer 2003;97:1663-71.
[4] Srivastava A, Patel HV, Kim S, et al. Delaying surgery for clinical T1bT2bNOMO renal cell carcinoma: oncologic implications in the COVID-19 era and beyond. J Clin Oncol 2021;39(6 Suppl):283.

${ }^{a} U C L$ Medical School, University College London, London, UK ${ }^{\mathrm{b}}$ Specialist Centre For Kidney Cancer, Royal Free London NHS Foundation Trust, London, UK

'Department of Pathology, Royal Free London NHS Foundation Trust, London,

UK

${ }^{\mathrm{d} D e p a r t m e n t}$ of Radiology, Royal Free London NHS Foundation Trust, London, UK

${ }^{\mathrm{e}}$ Royal Bournemouth and Christchurch Hospitals NHS Foundation Trust, Bournemouth, UK

${ }^{*}$ Corresponding author. Specialist Centre for Kidney Cancer, Royal Free London NHS Formation Trust, UCL Division of Surgery and Interventional Science, Pond Street, London NW3 2QG, UK. E-mail address: a.bex@ucl.ac.uk (A. Bex). 